\title{
UNA REESCRITURA DE THE TEMPEST DESDE LA PERSPECTIVA AFROAMERICANA: TAR BABY DE TONI MORRISON
}

\author{
M. ${ }^{a}$ Luisa Garcia González \\ marisagago@yahoo.es
}

Culture-bearing black woman, whose culture are you bearing? TONI MORRISON, Tar Baby.

\section{RESUMEN}

Tar Baby es una de las revisiones más creativas de The Tempest cuya originalidad reside no tanto en la reescritura de la obra de Shakespeare en sí, cuanto en la forma en la (pue Morrison aúna una obra canónica del eurocentrismo con una leyenda popular, representativa de la tradición afroamericana. ¿Puede la mujer de color triunfar en la soriedad blanca de boy en día sin renunciar a su herencia negra o se convertirá en una tar baby, un señuelo al servicio de la perpetuación del sistema, como lo fue en su momento la obediente hija de Prospero?

Palabras Clave: Poscolonialismo; Reescritura; Canon; Eurocentrismo; Tradición afroamericana.

\section{ABSTRACT}

Tar Baby is one of the most creative revisions of The Tempest. Its originality lies not so much in the rewriting of Shakespeare's play as in the way in which Morrison puts together a canonical eurocentric work with a popular legend of the Afroamerican tradition. Can a black woman succeed in today's white society without renouncing to her black heritage or will she become a tar baby in the process, a bait to perpetuate the system, as Prospero's obedient daughter was? 
KeY wORDs: Poscolonialism; Rewriting; Canon; Eurocentrism: Afroamerican tradition: The Tempest; Shakespeare.

The Tempest destaca como el texto más importante que se haya usado para articular el encuentro del hombre occidental con el otro y establecer un paradigma de las lecturas coloniales, dentro de un contexto discursivo colonial primero y poscolonial después. En el proceso de elaboración de la historia cultural, la obra ha suscitado numerosas reescrituras sobre todo en el ámbito de la novela de autoría femenina ya que son precisamente las mujeres las que, a través de la reivindicación que hacen en sus textos de otras mujeres y del papel femenino en textos mayoritariamente escritos por varones, recuperan las versiones que habían quedado relegadas en los bordes de la historia y sacan a la luz las particularidades, lo oculto o excluido del sistema patriarcal, racional y moralmente jerarquizado, que propugnaba el canon occidental.

Como en otras revisiones de The Tempest hechas por mujeres - No Telephone to Heaven (1987) de Michelle Cliff, Mama Day (1988) de Gloria Naylor o Indigo (1992) de Marina Warner-en Tar Baby (1981) de Toni Morrison, asistimos al descentramiento de Prospero a favor del nativo, históricamente desplazado a los márgenes y que aquí, sin embargo, cobra protagonismo.

Tar Baby es una de las revisiones más creativas de The Tempest, al situar a Shakespeare al lado de los cuentos populares afroamericanos de Uncle Remus. Éstos emergen de una tradición, la fábula de animales, profundamente arraigada tanto en África como en Europa y tratan del valor de la astucia de los más débiles para escapar de los más poderosos, ofreciendo al final una lección moral. Simbólicos de la relación amo/esclavo, los cuentos entran de lleno en la mitología de la tradición de la plantación, rearticulando el mito africano como respuesta a la esclavitud y enfrentándose a ésta por medio de tácticas que socavan y se burlan del amo blanco de un modo oblicuo y, con frecuencia, humorístico, al tiempo que aportan una pequeña esperanza de libertad, de final feliz, para el esclavo. Estos relatos aúnan así el entretenimiento con un mensaje codificado subyacente. En la tensa atmósfera racial de 1880 y 1890 ¿qué narrador de color se hubiera atrevido a contar este tipo de historias subversivas a sus amos blancos, si no era bajo el disfraz del bueno de «Uncle Remus»?

Uno de esos amos blancos, Joel Chandler Harris, recogió los cuentos dentro de la línea de puro divertimento para los blancos y, en cierta medida, para conservar una voz «pintoresca» que se estaba perdiendo. Lo que Harris - quien, a pesar de sus esfuerzos antropológicos, comulgaba con la creencia en la superioridad de la raza blanca- no vio, fue que las historias y leyendas que él guardaba para la posteridad, socavaban, precisamente, su propia cultura blanca.

El primer volumen de la colección de Uncle Remus Tales apareció en 1881, como Legends of the Old Plantation, y contenía historias tales como «Uncle Remus Initiates the Little Boy», «The Wonderful Tar-Baby Story», «A Story about Little Rabbits», o «Why the Negro is Black». El cuento de la tar baby, la muñeca embreada a la que todo irremediablemente se adhiere sigue siendo uno de los más populares de la colección. En él, Brer Fox, un granjero, intenta atrapar a un molesto conejo que le roba la comida, construyendo una tar baby, una muñeca hecha de alquitrán, muy atractiva a la vista pero mortalmente 
pegajosa si se la toca. Brer Fox la pone en medio del camino por el que tiene que pasar Brer Rabbit y espera escondido. Cuando el conejo, como es inevitable que suceda, queda pegado al alquitrán, el granjero, victorioso, propone varias maneras, cada cual más cruel, de deshacerse de él. Pero Brer Rabbit, más astuto, consigue burlarle en el último minuto, "Boil me in oil», «skin me alive», «roast me», «hang me», «but please, don't fling me in that briar patch,» suplica una y otra vez. El granjero cae en la trampa del conejo, haciendo precisamente lo que cree que es lo peor para éste. Según lo lanza entre las zarzas (the briar patch), Brer Rabbit comienza a saltar riéndose, «Born and bred in the briar patch. I was born and bred in the briar patch!»' para, acto seguido, esfumarse entre los matorrales.

Es significativo que sea el granjero blanco el creador de la tar baby. «In the original story, the tar baby is made by a white man. [Jadine] has to have been almost 'constructed' by the Western thing, and grateful to it» concreta Morrison (Taylor-Guthrie 1994: 102). Como tal, a pesar de que a Valerian Street, el granjero de Tar Baby, se le acusa de ser «one of the killers of the world», Jadine se reconoce como creación suya y, agradecida, lo defiende y apoya refiriéndose repetidamente a él como su benefactor $(205)^{2}$.

Como símbolo del capitalismo y del imperialismo americano, Valerian Street «is not the main character, but he certainly is the center of the world» dice Morrison (TaylorGuthrie 1994: 101). Lo que la autora pretende en Tar Baby es retirar a ese Prospero contemporáneo del centro, explorando lo que existe tras la figura del empresario triunfador, el generoso mecenas, y situar, en su lugar, a quien históricamente ha sido desplazado a los márgenes; hacer lo que algunos críticos denominan una novela «negra», es decir, reemplazar los estereotipos y mitos que el hombre blanco ha construido para el de color por la recreación de una mitología propia en la que resituar a esa tar lady de la iconografía africana. Como la propia Morrison dice, la novela trata de «desempolvar el mito y examinarlo detenidamente para ver que puede esconder» (Taylor-Guthrie 1994: 122).

La novela se abre en medio de una paradisíaca isla caribeña inventada por Morrison, en la que se ha construido su hogar un magnate americano, Valerian Street, el granjero blanco del folclore afroamericano que equivaldría al Prospero de la obra de Shakespeare. Dueño de una fábrica de golosinas, su fortuna tiene como base el azúcar, doble metáfora en la novela, tanto del expolio del colonialismo en el Caribe como del alquitrán del cuento, tan pegajoso como el caramelo, con el que está formada la tar baby. Retirado ya de los negocios, Valerian vive allí con su esposa Margaret, una belleza mucho más joven que él, y su servicio doméstico, Sydney y Ondine Childs, ambos de color, quienes llevan con él toda la vida. En las tareas domésticas ayudan también unos nativos, Gideon y Therese, a los que en la mansión conocen simplemente como «Yardman» y «Mary». En la isla se encuentra, además, la sobrina de los Childs, Jadine, una joven huérfana que ha sido criada por sus tíos bajo la tutela de Valerian, a quien debe su educación universitaria. Profundamente integrada en las prácticas jerárquicas de la estética eurocéntrica, Jadine ha interiorizado sus valores e ideales y es la Miranda que adora y defiende a su «padre», Valerian/Prospero, deslumbrada por los habitantes del «Brave New World» del glamour, —el mundo de la moda de París, Roma y Nueva York. Si Valerian es el Brer Fox del cuento, el dueño de la propiedad acosada por un proscrito, Jadine/Miranda es la tar baby, la muchacha que «cautiva» al invasor con su

\footnotetext{
I http://xroads.virginia.edu/-UG97/remus/tar-baby.html

2 Las referencias pertenecen a la edición de Vintage de 1997.
} 
atractivo físico. Joven, brillante y bella, portada de revistas como Elle y Vogue, y licenciada en Historia del Arte por la Sorbona, Jadine ha triunfado en el mundo blanco y se ha asimilado a éste olvidando «the ancient properties» de su raza. Aceptada y alentada por el poder, Jadine despierta de su sueño el día de su encuentro en París con una africana que la escupe al pasar a su lado como señal de desprecio por su falta de autenticidad y por haberse vendido a los nuevos amos. El episodio deja consternada a la joven, «the woman had made her feel ... lonely and inauthentic» (Tar Baby, 45) y su presencia en la isla es más producto de la huída de ese encuentro que del aparente deseo de pasar las navidades con los suyos.

Margaret espera también la llegada de su hijo Michael, quien finalmente no se presentará. En su lugar, es Son -el Caliban, en ocasiones Ferdinand, y, a la vez, Brer Rabbit de Tar Baby — quien llega a la isla y amenaza la aparente paz y la armonía de ese mundo que, sin embargo, oculta graves tensiones. Fugitivo de la ley y marginado social, Son pertenece a esa «great underclass of undocumented men» (Tar Baby, 167) de la que la voz narrativa nos da algunos ejemplos recogidos en las épicas nacionales: «Some were Huck Finns; some Nigger Jims. Others were Calibans, Staggerless and John Henrys» (Tar Baby, 167). Son es el Caliban negro, el rebelde que se niega a seguir las reglas y los valores del sistema blanco. Escondido en la magnífica casa de Valerian, donde, como Brer Rabbit, ha entrado para robar comida, Son pronto es descubierto. Sydney, el criado que se enorgullece de ser «one of those industrious Philadelphia Negroes» (59) está dispuesto a disparar al «swamp nigger» con el que no tiene ningún lazo en común y al que percibe como una amenaza para la colectividad de negros que "prosperan» en el sistema, «the man upstairs wasn't a Negro - meaning one of them. He is a stranger, a nasty and ignorant [...] nigger», afirma (Tar Baby, 101-2). Sin embargo, Valerian insiste en que Son permanezca en la casa y celebre con ellos la comida de Navidad. A ninguno se le oculta la razón. Como dice Sydney, «White folks play with Negroes. It entertains him» (Tar Baby, 163). Es la forma irónica de la autora de mostrar lo que los nuevos historicistas acuñarían como la estrategia del equilibrio entre subversión y contención. Valerian, consciente de su innata superioridad, puede permitirse el lujo de tolerar lo que quienes se sienten realmente amenazados no pueden y, precisamente, parte del interés de la novela reside en la alteración del juego de poderes en diversas esferas. Durante esos días, Son se transforma, de modo que de Caliban pasa a ser un Ferdinand pretendiente de Jadine, quien se enamora de él. En el marco de una grotesca cena de Navidad, a la que los criados negros son invitados, éstos, sentados a la mesa con sus señores y vestidos con sus mejores ropas, se sienten profundamente humillados por la actitud de Valerian; primero por su liberalidad con Son, luego por menoscabar su autoridad al no consultarles antes de expulsar a Gideon y a Therese, los nativos de color sorprendidos robando unas manzanas. Encolerizada, Ondine explota y revela el secreto que durante tantos años ha guardado: la esposa de Valerian, la bella Margaret, es, en realidad, «a white freak! [...] a baby killer!» (209), que había maltratado brutalmente a su hijo Michael cuando éste era un bebé. El descubrimiento fuerza a Valerian a reconocer su culpabilidad por haber preferido «no ver» el sufrimiento de su hijo durante todos aquellos años. Valerian es «culpable de inocencia». En el mundo construido para sí, un imperio donde lo controlaba todo, Valerian se ha tapado los ojos, sin embargo, y no ha querido ver lo que tenía delante pero tampoco puede ya continuar interpretando su papel de empresario benévolo y justo. Son le recuerda que no tiene derecho a encolerizarse con los caribeños por haber robado la fruta 
cuando los antepasados de Valerian han expoliado a los caribeños de todos sus bienes. El Valerian que antes había exclamado «I am being questioned by these people, as if, as if I could be called into question!» (Tar Baby, 207), con la misma ira que manifestaba Prospero en The Tempest ante la posibilidad de que alguien - su esclavo o los criados Trinculo y Stephano- pudiera rebelarse a su mandato, recibe ahora una contundente respuesta por parte de Son, quien, como Caliban hiciera en su momento, articula airadamente el nuevo sistema de explotación colonial.

Tras la crisis desencadenada durante la cena navideña, Jadine y Son se van juntos a Nueva York, donde viven un apasionado romance, aunque la visión de la ciudad es muy diferente para cada uno de ellos. Mientras que Jadine se mueve a sus anchas en la ciudad, «if ever there was a black woman's town, New York was it» (Tar Baby, 223), Son la define como «island of crying girls and men on tippy-toe» (222) y la convence para visitar Eloe, la pequeña comunidad rural del sur de la que él es originario. Son trata de mostrar a Jadine la sencillez y la pureza rural de Eloe como contraposición a la superficialidad de los valores cosmopolitas. Pero de la misma forma que él no puede vivir en el mundo blanco y sin raíces de Jadine, ella tampoco puede transigir con el mundo negro, primitivo y atrasado de Son. Eloe, en su pobreza, ignorancia y aislamiento, encierra todo lo «negro» de lo que Jadine ha luchado tan denonadamente por escapar. Anteriormente, en la isla, en una escena clave para el mito de la tar baby, Jadine, que había caído en un pantano de aguas sulfurosas y alquitranadas, se siente atrapada por las «swamp women», las míticas habitantes del pantano, que la acechaban en sus pesadillas. Ahora, en Eloe, Jadine siente aún más amenazada su libertad por la presencia de las «night women», los fantasmas raciales que la visitan en sus sueños y permanecen incólumes observándola y que, como Son, exigen el reconocimiento de su conciencia racial y la sumisión a una colectividad ancestral que la reclama:

The night women were not merely against her ... not merely looking superior over their sagging breasts and folded stomachs, they seemed somehow in agreement about her, and they were out to get her, tie her, bind her. Grab the person she had worked hard to become and choke it off with their soft loose tits. (Tar Baby, 264)

De vuelta a Nueva York, las discusiones se hacen más frecuentes y durante una última pelea que pondrá fin a su relación, Son renuncia a la educación eurocéntrica que Jadine, en su deseo de rescatarle de lo que ella percibe como «primitivismo», ha estado tratando de imponerle, «What the hell kind of education is it that they didn't teach you about Gideon and Old man and me?» (267) le pregunta Son. Enfurecido por el rechazo y el desprecio de Jadine de su cultura y de su propia familia, el Caliban de Morrison, como el de Lamming en Water with Berries, consuma la violación - solamente insinuada en The Tempest - de Jadine/Miranda, mientras le cuenta la leyenda de la muñeca embreada ${ }^{3}$. Rota la relación, Jadine vuelve a Isle des Chevaliers para recoger algunas de sus cosas antes de regresar definitivamente a París. Dolida con ella por haber huido

${ }^{3}$ Coincido en este punto con la opinión de Missy D. Kubitschek quien, siguiendo a John Duvall afirma que «a careful reading of Son and Jadine's last quarrel indicates rape» (Kubitschek 1998: 105). La escena de la narración de Son está punteada por las protestas de Jadine, «Don't touch me», «Quit! Leave me alone». Al final, «after he banged the bedroom door, she lay in wrinkled sheets, slippery, gutted» (Tar Baby, 273). 
con Son, sin preocuparse por la situación de sus tíos tras la crisis navideña, Ondine le reprocha, «A girl has got to be a daughter first [...] and if she never learns how to be a daughter, she can't never learn how to be a woman» (Tar Baby, 283). Cuando finalmente se va, después de recoger su magnífico abrigo de piel, símbolo del aspecto más superficial del mundo de los blancos al que ha accedido a través del de la moda, su tía duda incluso que sea Jadine quien les entierre a ella y a Sydney. Y cuando, de camino a París, encuentra en los lavabos del aeropuerto a Alma Estée, pasa de no reconocerla a despreciarla. Para ella, Alma Estée es un ser absolutamente primitivo, desprovisto de alma. Su visión de la niña es la de un animal, «un ciervo» piensa al observarla de cerca, y la única curiosidad que siente es la de dibujarla, precisamente por su aspecto pintoresco. Al final, en un calco de lo que sería la actitud de Valerian o de Margaret hacia la joven isleña, le da unas monedas y se despide de ella llamándola Mary. Como los blancos ricos instalados en la isla, Jadine no ha hecho ningún esfuerzo por aprender el nombre de los sirvientes. Para ella, como para Valerian y para Margaret, todas las mujeres de la isla son la misma y todas se llaman Mary. Alma Estée evidentemente la incomoda. Es la descendiente de "the diaspora mothers", pero niña todavia, aún no convertida en «the African woman [who] with a single glance from [her] eyes [...] could discredit your elements» (Tar Baby, 290). Jadine sólo ve su aspecto exterior y no es capaz de percibir su inocencia ni el mundo de fantasía que aflora mezclado con sus palabras. La peluca que lleva Alma Estée es, para Jadine, un elemento pintoresco y llamativo que marca su primitivismo. Son, sin embargo, contempla horrorizado a Alma Estée «in a wig the colour of dried blood. Her sweet face, her midnight skin mocked and destroyed by the pile of synthetic dried blood on her head" (301-2), y contrasta la grotesca peluca artificial con «the midnight skin and antelope eyes» de la niña, con imágenes tan vivas como la de «a baby jaguar with lipstick on, $[\ldots]$ an avocado with earrings» (302), que nos dan una idea del horror que la visión de la niña, inocente y natural, provoca al disfrazarse con la barata peluca occidental.

En una novela de final abierto Jadine, quien abandona su mundo negro para instalarse en Europa y evadirse allí de sus fantasmas, se nos muestra como la «traidora a la raza» de la que habla La Vallee (1997). Antes, Son ha aludido a un tema central para la cuestión que nos ocupa: «People don't mix races, they abandon them or pick them» (Tar Baby, 272). Jadine ha hecho su elección y opta por la cultura blanca.

Son vuelve a la isla caribeña tras los pasos de Jadine. Literalmente atrapado por la tar baby que significa su pasión por la joven, no tiene capacidad de elección. Es Therese, la descendiente de la mitológica raza de esclavos ciegos, quien le da la posibilidad de elegir, llevándolo al otro lado de Isle des Chevaliers, donde podrá escoger entre el sometimiento a la raza blanca, que significa seguir a Jadine, o la libertad que entraña unirse a una banda de jinetes ciegos, antiguos esclavos, vivos en la leyenda de la isla. Al pisar tierra firme, Son avanza hacia los árboles y comienza a correr. No se sabe si hacia la mansión en busca de Jadine o en pos del mito que sustenta su identidad. El rítmico sonido de su carrera, «Lickety-Split, Lickety-Split Lickety-Split Lickety-Split» como el de Brer Rabbit cuando, liberado, huye hacia su «briar patch» es el punto final de la obra. De hecho, hablando de las razones para darle este final a la novela su autora dice, «I want [Son] to be left with a wide-open choice at the end. [...] When he climbs off the rocks and stands up the trees step back to make a way, and then to have him go lickety-split is 
to suggest the rabbit returning to the briar patch" (Conversations, 1994: 107). De la misma forma, a la pregunta de Nellie McKay, «Can you tell me why you ended Tar Baby with «lickety-split»? Morrison responde,

I wanted it to have the sound of the Tar Baby story, which is lickety-split towards or away from or around the briar patch. But I also wanted to suggest that his journey is Son's choice -although he did not think it up. Therèse did. There is a strong possibility that he joins or is captured by the horsemen- captured by the past, by the wish, by the prehistoric times. (McKay 1988: 150)

Cuarta de las novelas escritas por Toni Morrison, tras The Bluest Eye, Sula y Song of Solomon, en las que la escritora dirigía su atención exclusivamente a la comunidad de color, Tar Baby es la primera en extender su campo de acción, introduciendo y dando cierto protagonismo a personajes de raza blanca para exponer los conflictos raciales en la base de la novela. Los personajes de color en Tar Baby muestran hasta qué punto esta comunidad se ha alejado de sus orígenes y sus valores, atrapados por el «tar baby» de la cultura «materialista» blanca de la que no disfrutan más que las migajas: los criados, esos «genuine Philadelphia Negro mentioned in the book of that name» - un «título» que se ha otorgado Sydney a sí mismo y que se repite con ironía a lo largo de la novela- esperan, tras toda una vida de servicio, la jubilación prometida por Valerian, que puede verse comprometida por sus cambios de humor. El exotismo de Jadine añade glamour al lujo de los blancos, para quien una hermosa mujer negra no es sino un objeto más de incitación al consumo de sus productos, aparte de reforzar sus cánones (blancos) de belleza. Jadine no comprende que ella es el objeto «glamoroso» que añade un plus de color, exotismo y valor al coche, al visón, o a la joya junto a los que aparece en Vogue o en Vanity Fair. Lo que ella toma por integración en el mundo de los blancos no es sino una utilización por parte de éstos de la tar baby en beneficio de sus propios intereses, reflejados en el extremo contrario: la peluca que la inocente Alma Estée se pone que, como Son observa, es imagen grotesca de un cachorro de jaguar al que se le hayan pintado los labios. La rica herencia cultural de la comunidad negra se ha contaminado, perdida sin remedio en personajes de color que han olvidado a qué comunidad pertenecen. La única solución parece ser la que propugna el Caliban de esta historia, «white folks and black folks should not sit down and eat together» (Tar Baby, 211), muy en la línea de su lema: «People don't mix races, they abandon them or pick them» (272). Con todo, el conflicto principal es el que libra en su interior la protagonista, Jadine. Ella es la "traidora a la raza», la mujer que ha renunciado a su herencia cultural en favor de la cultura y forma de vida blancas. Por ello, se verá perseguida y acusada de falta de autenticidad por toda una comunidad de mujeres de color, descendientes de Sycorax, a la que la propia Morrison afirma pertenecer y que, fieles a sus raíces, llevan consigo su tradición y cultura, y aparecen en los sueños de Jadine, mudos testigos acusadores del abandono de ésta de su identidad racial. Con su silenciosa presencia, estas «mujeres nocturnas» reclaman a la hija pródiga.

Siguiendo la teoría de Edward Said, Jadine incurre en una nueva «mimicry of the centre» que procede del deseo no sólo de ser aceptada sino «adopted and absorbed» (Ashcroft et al 1989: 4). La voz narrativa nos dice de sus protagonistas, «each one bore the culture to save the race in his hands» pero, en el caso de Jadine, se pregunta, 
«Culture-bearing black woman, whose culture are you bearing?» (Tar Baby, 272). La Miranda de color de Morrison ha abrazado la cultura blanca, en detrimento de la propia.

En «Unspeakable Things Unspoken» (1989: 1-34), Morrison sugiere la relectura de textos americanos canónicos, que generalmente han sido escritos por hombres para elucidar los temas raciales y lo que constituye tabú. En esta línea, Tar Baby, como el resto de las reescrituras mencionadas, se opone a las lecturas idealistas de The Tempest, en las que la obra funcionaba como legitimación del discurso de poder occidental. Morrison, como tantos y tantas escritoras poscoloniales, usa la obra de Shakespeare no como inspiración estética sino para proponer un debate sobre raza, cultura e ideología. Tar Baby adopta una posición revisionista sobre el papel de The Tempest en la ideología colonial. Sin embargo, la figura central de la que de Morrison se apropia no es Caliban. En su lugar, siguiendo las coordenadas de las prácticas feministas, convierte a Miranda en la protagonista.

La verdadera originalidad de la novela de Morrison reside, no tanto en la reescritura de The Tempest en sí, cuanto en la forma, en la que ha aunado una obra canónica del eurocentrismo con una leyenda popular representativa de la tradición afroamericana, para responder a la pregunta de hasta qué punto la mujer de color de hoy en día puede triunfar en la sociedad blanca sin renunciar a su herencia negra y sin convertirse en la obediente hija de Prospero, esto es, una tar haby al servicio de la perpetuación del sistema. No olvidemos que la Miranda de Shakespeare es también una tar baby, el señuelo que atrae al hijo de Alonso, el rey de Nápoles, y lo "cautiva» mediante un matrimonio que hace posible que Prospero recupere con creces su poder perdido. El principio básico que relaciona a la tar baby del mito afroamericano con la Miranda de Shakespeare es que ambas han sido construidas por el patriarca blanco y las dos son cebos de los que el poder se vale para conseguir más poder y para reproducirse.

Morrison nos presenta a una Miranda no contemplada en otras reescrituras de The Tempest. Miranda es aquí el instrumento, la «traidora a la raza», la «tar baby» de la que el hombre blanco se sirve para atrapar al de color en su propio beneficio. Jadine/Miranda es la «yalla», la negra de piel clara que ha olvidado las antiguas virtudes de su raza para abrazar la representación más externa, trivial y efímera del mundo de los blancos, significativamente representado en el de la moda. Es la espectacular modelo con ojos de "color visón", portada frecuente de revistas de lujo como Vogue y Vanity Fair, una Noemi Campbell de ficción, la «pantera negra» cuyo exotismo añade glamour al lujo de los blancos, reafirmando sus cánones de belleza, y convertida en objeto de incitación al consumo. Como tal, Jadine es incapaz de «ver» el simbolismo que le ofrecen las imágenes de las mitológicas mujeres nocturnas que la desvelan, a las que desprecia y teme a la vez.

Por su parte, Caliban aparece en la novela de Morrison en una doble reconfiguración: Son (Hijo) es tanto el «hag-seed», «lying slave», y «howling monster» del texto canónico de Shakespeare como el Brer Rabbit de la tradición oral afroamericana. El nombre que Morrison le da es profundamente simbólico y con él reivindica el reconocimiento que parte de la crítica ha querido ver en Prospero de Caliban como hijo suyo, «this thing of darkness I acknowledge mine» (5.1.275-6).

Jadine es una joven «triunfadora» que, sin embargo, ha perdido su autenticidad y resulta artificial y vana. Desdeña tanto la vida que han llevado sus tíos, criados sempiternos de Valerian, como sus consejos, y adora a este último, de quien, social y culturalmente, se siente más cerca. Jadine desprecia, sobre todo, el pueblo de Eloe, enclave remoto y 
perdido al que califica como «a burnt-out place». La pequeña comunidad rural de color es para Jadine un lugar sin futuro y declara, «All that Southern small-town country romanticism was a lie, a joke, kept secret by people who could not function elsewhere» (262).

La belleza de Jadine sigue los cánones de la ideología patriarcal blanca. Su cabello largo y liso nada tiene que ver con el prototipo africano que Una Marson reivindica en su poema «Kinky Hair Blues» ${ }^{4}$. Su piel es tan clara que los nativos de la isla —mucho más oscuros que ella - no dudan en llamarla «yalla» y advertir a Son «Look out. It's hard for them not to be white people. [...] Yallas don't come to being black natural-like. They have to choose it and most don't choose it» (Tar Baby, 156). Morrison la contrapone a la mujer a la que Jadine ha conocido en París, la «auténtica» mujer africana, conectando los rasgos afroamericanos con los africanos en términos positivos, «that woman's woman -that mother / sister / she; that unphotographable beauty» (Tar Baby, 43). Una mujer que, a pesar de sus rasgos exuberantes y de tener una piel profundamente oscura, posee, sin embargo, una «trascendent beauty» capaz de dejar a todos con la boca abierta a su paso.

Otras reconfiguraciones poscoloniales de Miranda, ya fueran blancas o de color, buscaban transgredir el icono de belleza rubia, blanca y occidental de la hija de Prospero, y elegían, identificándose con el elemento negro ${ }^{5}$. Jadine, por el contrario, rechaza absolutamente esa africanización: «I want to get out of my skin and be only the person inside —not American- not black - just me» (45). Su temor a las mujeres nocturnas está basado, sobre todo, en el hecho de que éstas puedan arrebatarle su libertad y su independencia, "grab the person she had worked hard to become and choke it off with their soft loose tits» (264). Para Susan Lydon (1981), Jadine está atrapada entre sexo y raza. Por un lado, permanecer fiel a la libertad que se ha ganado como mujer significa resistirse a la insistencia masculina de Son en que interprete el papel sumiso de «fat black lady serving pies in the church basement» al que éste alude en repetidas ocasiones. Por otro, surge la pregunta crucial: para ser fiel a su herencia negra idebe Jadine sacrificar su éxito dentro de la cultura blanca? En el contexto, esta Miranda de color vive en una dualidad sin resolución posible. El dilema al que se enfrenta es el de identificarse con su «opresor»o con su pueblo; sin embargo, el retrato que hace Morrison de Jadine/Miranda es más complicado y ambiguo de lo que pueda afirmarse a primera vista. ¿Quién entre sus protagonistas, ya sean blancas o negras, asumiría, hoy en día, el papel tradicional de «black lady serving pies in the church basement» al que Son quiere reducirla? En un artículo de Ann Rayson (1998: 1-11) donde se compara el papel de las protagonistas de Quicksand, la obra de Nella Larsen de 1928 y Tar Baby (1981), la autora cita las palabras de Trudier Harries, quien, en Fiction and Folklore, comentaba que es muy fácil no tenerle simpatía a Jadine porque «African American folk culture has not prepared us well for a female outlaw ...: Women who dare to assert individualistic values over communal ones are summarily put in their places». Por el contrario, «men who follow individualistic paths are deemed heroic» (Rayson 1998: 7). Helga Crane, la protagonista de Quicksand, cae en

4 «I like me black face/And me kinky hair/Hate dat ironed hair and dat bleaching skin». (Donell and Welsh 1996: 137).

5 En revisiones de autoría femenina como No Telephone to Heaven (1987) de Michelle Cliff, Mama Day (1988) de Gloria Naylor o Indigo (1992) de Marina Warner. 
el estereotipo, mientras que Jadine lo rechaza. Según Rayson, la necesaria victimación de Helga apela a nuestra simpatía y, sin embargo, castigamos a Jadine por defender los valores individuales por encima de los comunales. Ambas novelas critican las reducidas posibilidades que se les presentan a las mujeres afroamericanas, pero su resultado es muy diferente. Rayson dice que «Helga chooses to be black and sinks into quicksand. Jadine recognizes the trap of Eloe, so chooses Europe and the peacock's role» (1998: 8). Según Harries, la cultura popular afroamericana no está aún preparada para una Jadine que quiere para sí un papel distinto de los que tradicionalmente han desempeñado las mujeres de color. Jadine es una mujer moderna, producto, en parte, de la ideología feminista, y ha abrazado los valores capitalistas del sistema social y político occidental. Como tal, adora el glamour, las fiestas y las grandes urbes. En Nueva York, una ciudad poblada por mujeres de color independientes y seguras de sí mismas, de las que Morrison hace una encendida valoración - «if ever there was a black woman's town, New York was it» (123) - es donde Jadine se siente realmente en casa. Sin embargo, sin ancestros que marquen las pautas de su vida, a Jadine le es sumamente difícil descubrir sus orígenes en esa comunidad de mujeres de color. Como Miranda, Jadine es huérfana, desarraigada y sin tradiciones, y tiene que encontrar su propio camino y asumir lo que le falta para lograr la autenticidad. Ondine intenta explicárselo diciéndole,

Jadine, a girl has to be a daughter first. And if she never learns how to be a daughter, she can't never learn how to be a woman. I mean a real woman: a woman good enough for a child; good enough for a man - good enough even for the respect of other women (Tar Baby, 283).

Pero son los propios Childs quienes han animado a Jadine a desconectarse culturalmente, como signo de su éxito y la han alienado de su propia cultura de color, convirtiéndola en alguien que prefiere a Picasso a las máscaras Itumba y el «Ave María» a la música gospel.

Parece que la sugerencia de Morrison es que la raza, especialmente la negra, no es tanto cuestión de genética, como de cultura. Sin un coro de «mamas» y de tías que le ayuden, la mujer de color corre el riesgo de desarraigarse, de vivir en una diáspora permanente. Jadine no ha aprendido lo que necesita saber para ser la «real woman» que describe Ondine. Nunca ha conocido las «ancient properties» de la comunidad de las mujeres de color. Al dedicar Tar Baby a las mujeres de su familia, Morrison sugiere la importancia de ese vínculo. No es que Jadine haya querido traicionar a su raza. Su gran equivocación ha sido la de no apoyarse en la fuerza de aquéllas que la han precedido. Al final de la novela, Jadine sigue siendo una huérfana, una tar baby en manos del gran patriarca blanco que rechaza a la comunidad de mujeres ancestrales de color, decidida a vivir su vida según sus propias reglas. En el avión hacia París, comprende que quizá esto es lo que Ondine ha querido decirle, «A grown woman did not need safety or its dreams. She was the safety she longed for» (292). A la Helga Crane de Quicksand (1928) no se le permite ser libre, pero Jadine Childs sí lo es. Escrita en la era de los ochenta, Morrison le da la posibilidad de elegir. Como dice Rayson, «In the late twentieth century, it is the African American male who is trapped» (1998: 8).

Morrison recrea una ambientación geográfica en una isla paradisíaca del Caribe y se centra en temas como el colonialismo, el racismo, las relaciones de poder, la dualidad 
Naturaleza/Civilización y el miedo al mestizaje, que sugieren un estrecho paralelismo intertextual con The Tempest. Sus personajes también son un eco de los de la obra de Shakespeare y ejemplifican los temas del colonialismo y de la estética colonial en cuanto a orden jerárquico. Si Shakespeare, el epítome de la tradición literaria canónica occidental, sitúa a su mago imperialista, occidental, patriarcal y blanco en el centro del universo discursivo de su obra, Morrison utiliza al bardo como contrapunto de la emergente tradición de las escritoras contemporáneas de color, y a la figura de Prospero - que en su obra lleva el nombre del emperador/granjero romano, Valerio - para subvertir y desconstruir el texto shakespeariano.

Valerian Street es un poderoso patriarca, icono del imperialismo americano, cabeza de un emporio construido sobre la base de la industria del azúcar en el Caribe y dueño de una extensa propiedad en una de sus islas. A través de él, Tar Baby nos ofrece una visión del colonialismo contemporáneo edificado sobre unas estructuras sociales y económicas históricamente injustas. Es muy significativo que su riqueza se sustente en la producción de golosinas cuyos ingredientes principales, el azúcar y el cacao provienen del Caribe. Isle des Chevaliers recrea el ambiente decadente de una antigua plantación azucarera caribeña donde Valerian/Prospero no sólo ejerce el poder del amo en su propiedad, sino que también determina los movimientos de su esposa y de cuantos le rodean y, además, controla la naturaleza en forma de un invernadero artificial con toda clase de artilugios entre los que no falta el hilo musical permanentemente emitiendo música clásica.

Como Prospero, Valerian es también un «exiliado» de la civilización, de la que vive aislado, aunque tiene el poder -intelectual y económico- para controlar al resto de los personajes. Igual que a él, a Valerian se le presenta como centro del eurocentrismo y de su modelo moral y estético. Sin embargo, Morrison subvierte al personaje al despojarlo de su poder y convertirlo en un anciano senil a merced de sus criados negros al final de la novela. Tras descubrir que su esposa había maltratado sistemáticamente a su único hijo cuando éste era un bebé, Valerian se retrotrae a un mundo propio; su senilidad es, para Kubitschek (1998: 96), otra forma de retirarse, de no querer ver, de negar su responsabilidad. Como argumenta Jan Furman en su estudio sobre Morrison (1996: 46-65), Valerian no es un ser malvado; nada de lo que ha hecho ha sido malintencionado. Morrison nos lo presenta como alguien esencialmente inconsciente del daño que ha causado y ha permitido que otros causen. Su nombre, relacionado también con la valeriana, la planta de uso sedante, le aleja del emperador que todo lo controla. En su letargo, ignora que su presencia en el Caribe es una extensión del colonialismo occidental o que expulsar a Gideon y a Therese por robar manzanas es inmoral - si se tiene en cuenta la usurpación que han sufrido de su lugar y su tierra en la historia-e incluso desconoce los abusos a los que su esposa ha sometido a su propio hijo. Valerian se ha creado un falso imperio y no ha querido ver nada más; es el Prospero que se retirara entre sus libros en Milán, abandonando sus responsabilidades y dejando que le despojaran de su ducado. En su caso, el crecimiento controlado de las plantas de su invernadero es un símbolo de su propio control, pero ese control de la naturaleza salvaje es tan artificial y estéril como su propia presencia en Isle des Chevaliers. No obstante, el centralismo de Valerian, símbolo de la cultura de la que procede, es inextinguible y, como tal, se contempla en el texto hasta el final: «master, patient, baby -it don't matter. He's still the centre of everything» (Tar Baby, 281). 
El matrimonio de sirvientes tiene en Valerian su modelo estético: exhiben las mismas pautas de comportamiento, visten de la misma forma, y comparten la ideología de sus «amos». Llamados "petty bourgeois», se mueven entre dos mundos, el de la clase dominante al que no pueden acceder, y el del pueblo africano que rechazan. Sydney y Ondine - al igual que su sobrina - se identifican más con la cultura de sus señores que con la propia. Víctimas de un falso sueño americano, sus vidas están definidas por su «pertenencia» a Valerian y, en aras de conseguir una seguridad material, han dejado atrás sus raíces. Su apellido, Childs, denota - como antes lo había hecho el nombre de Son-que son verdaderamente los hijos de Valerian, obedientes y dispuestos a todo lo que éste les mande. A pesar de la humillación de verse tratados como niños, comparten la ideología racista y capitalista de los Street. En consecuencia, se sienten «Philadelphia Negroes», y consideran a Son y a los nativos de la isla «niggers».

Son, el personaje del paria negro en la cultura occidental, supuesto violador de mujeres blancas, es el factor que viene a desbaratar esta jerarquía estética. Para Margaret y para los negros «blanqueados» de la casa, representa al «swamp nigger» (100), como Sydney le llama. Este nuevo Caliban reintroduce los valores de la naturaleza reprimidos o distorsionados en la estética eurocéntrica. Su relación con Jadine concuerda inicialmente en muchos puntos con la de Caliban y Miranda en The Tempest. Tanto ella como Margaret temen que las pueda violar. Jadine le advierte a Son, «You rape me and they'll feed you to the alligators» (103); como Miranda, lo rechaza llamándolo «ugly barefoot baboon» (104) y más tarde intenta educarlo inscribiéndolo en cursos y pagando el importe de las matrículas.

Morrison se hace eco de la aversión que experimentan Prospero y Miranda por las pasiones supuestamente animales de Caliban y su fracaso en seguir sus enseñanzas. Incluso la forma de hablar de Jadine refleja su creencia en dos polos opuestos y excluyentes: blanco/negro y civilizado/animal. El hecho de que a Son se le acuse repetidamente de querer violar a Jadine y a Margaret en Tar Baby sugiere la misma preocupación que aparecía en The Tempest, trasladada ahora a un marco americano, en el que el hombre de color sirve como pantalla contra el miedo al mestizaje. Prospero había acusado a Caliban de intentar violar a su hija, «thou didst seek to violate / The honour of my child.» (1.2.3478); ahora, desde la perspectiva blanca y racista de esta Miranda de color, Son/Caliban se presenta como un negro violador de mujeres blancas. Morrison critica con énfasis esta dinámica del imperialismo sexual en un largo pasaje en el que constantemente repite «he had not followed the women» (133-138).

En la dualidad Naturaleza/Civilización, Jadine tiene parte de las dos; no sólo es una bella modelo, sino también estudiante de Historia del Arte. Tar Baby muestra el modo en que la estética tradicional europea seduce a Jadine. Una forma es la de reconfigurar la belleza y el arte mediante la confrontación de Jadine con un personaje femenino de color y la otra mediante el uso del mundo natural del paisaje de la isla. En un principio, Jadine vuelve a la isla tratando de huir de la turbación que creara en ella esa mujer africana «too much hip, too much bust...» (42) que sugiere fertilidad y abundancia y es un eco del propio paisaje de la isla «the island exaggerated everything. Too much light. Too much shadow. Too much rain. Too much foliage and much too much sleep» (66). Tanto la mujer como la isla exceden el patrón de belleza eurocéntrica de Jadine. Como Valerian, Jadine parece incapaz de apreciar la naturaleza a menos que haya sido artificialmente controla- 
da. La exhuberancia del paisaje y de los rasgos de la mujer le producen un sentimiento de ansiedad como le ocurriera a Edward Rochester en la Jamaica poscolonial de Wide Sargasso Sea (Jean Rhys, 1966). Atraído y a la vez repelido por la carga de sensualidad de la isla, se manifestaba de forma casi idéntica a Jadine: «everything is too much. [...] Too much blue, too much purple, too much green. The flowers too red, the mountains too high, the hills too near» (Wide Sargasso Sea, 1997: 42).

El alquitrán es un símbolo central en la novela y hay numerosas alusiones directas relacionadas, además, con la tar baby. En una escena clave en la novela, Jadine entra en el bosque y comienza a hundirse en una sustancia oscura, espesa y viscosa de la que lucha denodadamente por salir, que prefigura metafóricamente a la comunidad de mujeres de la tradición afroamericana que tienen «atrapado» a Son y que desean también apropiarse de ella. Cuando éste la encuentra, cubierta de la pegajosa sustancia negra, se burla de ella, «That's where the swamp women live [...]. They mate with the horsemen up in the hills» (185). Posteriormente la acusa de ser una tar baby, la creación engañosa del hombre blanco para atacar por sorpresa al de color, «advance bitch, housebitch, welfare office torpedo, corporate cunt, tar baby, side-of-the-road whore trap» (221). Él es el Brer Rabbit del cuento afroamericano que ha irrumpido en la propiedad del granjero; Jadine la tar baby, construida como tal para atraparlo, y por ello, cuando luego la condene como herramienta de la que se vale el mundo blanco, le contará la historia.

Tanto Jadine como Son son herededos de la leyenda de tar baby y ambos intentan arrancar al otro de lo que les aprisiona, «each was pulling the other away from the maw of hell -its very ridge top. Each knew the world as it was meant or ought to be. One had a past, the other a future, and each one bore the culture to save the race in his hands" (272). Morrison plantea los dos extremos del conflicto que amenaza al pueblo afroamericano: la disolución en la cultura blanca obliterando sus raíces, su historia y su propia cultura o el anclaje en una fantasía de evasión, en un mito romántico primitivista que redunda en la marginación y la miseria.

Como ocurriera con Caliban en The Tempest, Son resiste todos los intentos de Jadine por educarlo y la ataca por actuar y pensar como si fuera blanca, por ser el instrumento creado por el hombre blanco para atrapar al de color. «You think I won't do all that company shit because I don't know? I can do anything! Anything! But I'll be goddamn if I'll do that" (272-73). Ya antes se ha expresado en los mismos términos: «I don't want to know their laws» (Tar Baby, 265). El poder es blanco: el gobierno, las leyes y la educación confluyen en imponer su supremacía en todos los ámbitos, en detrimento de la cultura negra, perpetuamente relegada al polo de lo inferior. Por ello, acusa a la joven de que, a pesar de haber ido a la universidad, no ha aprendido allí nada de cuanto afecta a los suyos. «What the hell kind of education is it that didn't teach you about Gideon and Old man and me?» (267). Su propia historia y su pasado han sido obliterados, por lo que es preciso recuperarlos para poder reconstruir una identidad propia y digna y por eso la increpa «until you know about me you don't know nothing about yourself» (267). Son es también, desde el comienzo de la novela, alguien en busca de su propio yo, en proceso constante de conocerse a sí mismo. Morrison concluye, «One had a past, the other a future and each one bore the culture to save the race in his hands. Mama-spoiled black man, will you mature with me? Culture-bearing black woman, whose culture are you bearing?» (Tar Baby, 272). 
Morrison construye sus figuras como representaciones de los polos extremos de la tensión que divide y amenaza al pueblo afroamericano. Su novela no puede por menos de concluir con un desenlace abierto ya que la tensión es, hoy por hoy, irresoluble. En este sentido, difiere radicalmente de The Tempest, exponiendo la falsedad de las reconciliaciones literarias obedientes a una estética dictada por el género literario o a una justicia poética que traiciona a la del mundo real.

Tar Baby es una novela de construcción circular y de final abierto, con un prologo y un epílogo paralelos, ya que en ambos se nos presenta a Son nadando hacia la isla guiado por manos femeninas. Comienza con una afirmación, «He believed he was safe» que, sin embargo, se va a subvertir inmediatamente, demostrando que la realidad es otra. La confrontación entre lo imaginado y lo real viene subrayada por la lucha inmediata con la corriente marina que casi lo ahoga. Nada más sumergirse en el mar, se ve absorbido por una corriente personificada como una mujer de garganta húmeda y manos insistentes que estrecha su «bracelet» en torno a sus tobillos y le empuja hacia un renacimiento, «a newborn baby» (119). Su encuentro con esta peligrosa mujer de agua presagia el que tendrá primero con Jadine que cambia el curso de su vida, y el del final de la novela, cuando otra mujer, Therese, vuelva a dirigir su destino.

En Black Feminist Criticism Barbara Christian señala que al final de la novela «we are still left with the dilemma of Tar Baby, for Son moves to another world that has little impact on this one, and Jadine cops out to a world of values that eventually must be a dead end, if not for her, most decidedly for her own» (1985: 69). Esta ambigüedad ha sido extensamente criticada por una gran parte de la crítica y de los lectores en general. En una entrevista con Judith Wilson (en Danille Taylor, 1994: 134) Morrison contesta a estas críticas diciendo: «it would be nice... to have a nice book in which you have two attractive people and they resolve their situation and hold hands and walk off into the sunset». Un final feliz, pero, añade la autora, «the problem has been put in the wrong place, as though it's a sexual battle, not a cultural one».

Tar Baby resulta ser la novela menos popular entre las de la escritora. Adolece de una "disjointed quality» (Karen Carmean 1993: 62-62) que puede resultar frustrante al lector. En mi opinión, esta frustración deriva no tanto de la incapacidad, por parte del lector, de reconocer la alegoría racial, la rearticulación posmoderna del mito o la investigación de la variedad de formas a través de las que entender el mito que lleva a cabo Morrison en la novela y que le da un final tan ambiguo, cuanto de esa «ambición creativa» a la que alude Carmean que hace que, en su afán por elevar a sus personajes a la categoría de mito, y de reconciliar el mundo de la naturaleza con el de la civilización, tienda a la «exageración dramática» (John Irving 1981: 1) y pierda credibilidad. La poca profundización en la descripción de los personajes, que aparecen casi como bocetos, siempre desdibujados; la descripción de la relación, apasionada y violenta, entre Jadine y Son, que a menudo induce al lector a creer que está ante la típica novela «rosa» - lo que ocasiona que se tienda a pensar más en el conflicto de carácter sexual que en el cultural, y a buscar un final feliz entre la pareja en lugar de asumir un final abierto a todo tipo de posibilidades- son otros factores que han incidido en la impopularidad de la novela.

Sin embargo, la importancia de Tar Baby radica en que la autora ha sabido aunar la obra canónica que The Tempest representa con la tradición afroamericana, para hablar no ya de forzadas reconciliaciones entre razas, entre amos y esclavos, necesariamente falsas, 
sino de la necesidad de reconciliación con la historia propia. La necesidad de «aprender a ser hija», de la que le habla Ondine a Jadine hacia el final de la novela y reconocer a sus auténticos padres. Con la proliferación de símbolos padre-madre / hijo-hija, que vemos acompañando a la circularidad de la novela, Morrison subraya una y otra vez el hecho de que los hombres y mujeres, los pueblos, en definitiva, no se conocen a sí mismos hasta que no exploran y aceptan su pasado. Valerian y Margaret han de ver, reconocer y expiar el suyo. Jadine y Son siguen su búsqueda, sin señales claras de conseguirlo, tan sólo atisbos que permiten, no obstante, albergar una esperanza.

\section{REFERENCIAS}

ANDERSON, Linda 1990: Plotting Change. Contemporary Women's Fiction. Londres: Amold . AsHCROFT, Bill, Gareth GRIFFITHS and Helen TiFFIN 1989: The Empire Writes Back: Theory and Practice in Post-Colonial Literatures. Londres: Routledge.

BAYM, Nina 1986: «Melodramas of Beset Manhood: How Theories of American Fiction Exclude Women Authors». The New Feminist Criticism. Essays on Women, Literature and Theory. Elaine SHOWALTER (ed.). Londres: Virago.

Bıork, P. B. 1992: «Tar Baby: The Presence and Absence of Self and Place». The Novels of Toni Morrison. The Search for Self and Place Within the Community. Nueva York: Peter Lang. 111139.

Carmean, Karen 1993: Toni Morrison's World of Fiction. Nueva York: The Whitston Publishing Company Troy. 62-79.

Christian, Barbara 1985: Black Feminist Criticism. Perspectives on Black Women Writers. Berkeley: University of California.

DONNELL, Alison \& WELSH, Sarah L. (eds). 1996: The Routledge Reader in Caribbean Literature. Londres y Nueva York: Routledge.

Furman, Jan 1996: Toni Morrison's Fiction. Carolina: Univ. South Carolina Press.

HARRIEs, Trudier 1991: Fiction and Folklore: The Novels of Toni Morrison. Knoxville: University of Tennessee.

Kubrtschek, Missy Dehn 1998: Toni Morrison. A Critical Companion. Westpont, Connecticut, Londres: Greenwood Press. 91-113.

LA VALLEE, Andrew W. A. 1997: “'Faces as Black as His But Smug' - The Race Traitor in Morrison's Tar Baby». Online Internet. 1 Mayo 1997. http: //ocaxpl.cc.oberlin.edu/ alavalle/morrison.html

LYDON, Susan 1981: «What's an Intelligent Woman To Do?» The Village Voice, 1-7. July, 1981.

McKaY, Nellie Y. (ed). 1988: Critical Essays on Toni Morrison. Boston, Massachusetts: G.K. Hall \& Co.

MORRISON, Toni. 1997 (1981): Tar Baby. Nueva York: Vintage.

- 1989: «Unspeakable Things Unspoken: The Afro-American Presence in American Literature» Michigan Quarterly Review 28, Winter 1989: 1-34.

NiCHOLs, Grace 1995: "I is a long memoried woman», en The Post-Colonial Studies Reader. Ashcroft, Griffiths, Tiffin (eds.). Londres y Nueva York: Routledge. 146.

Novy, Marianne (ed.) 1993: Cross-Cultural Performances. Differences in Women's Re-Visions of Shakespeare. Urbana y Chicago: University of Illinois Press.

- 1999: Transforming Shakespeare. Contemporary Women's Re-Visions in Literature and Performance. Nueva York: St. Martin's Press. 
O’Meally, Robert G. 1988: «Tar Baby, She Don' Say Nothin'», en McKay, Nellie (ed.): Critical Essays on Toni Morrison. Boston, Massachusetts: G.K. Hall \& Co.

OrGEL, Stephen (ed.) 1998: The Tempest, de William Shakespeare. Oxford: Oxford University Press.

PEACH, Linden 1995: Toni Morrison. Londres: McMillan. 75-92.

- 1998. Toni Morrison. Londres: McMillan.

RAYSON, Ann 1998: «Foreign Exotic or Domestic Drudge? The African American Woman in Quicksand and Tar Baby.» Melus, Summer, 1998. 1-11. http://www.findarticles.com 4.10.01.

Rhys, Jean 1997 (1966): Wide Sargasso Sea. Harmondsworth: Penguin.

RYAN, J. S. 1997: "Contested Visions / Double-Vision in Tar Baby» Critical and Theoretical Approaches. Toni Morrison. Ed. Nancy Peterson. Baltimore y Londres: The John Hopkins University Press. 63-87.

TAYLOR-GUTHRIE, Danille (ed.) 1994: Conversations with Toni Morrison. Jackson: University Press of Mississippi.

WaLTHER, Malvin L. 1993: «Toni Morrison's Tar Baby: Re-Figuring the Colonizer's Aesthetics», en Cross-Cultural Performances. Differences in Women's Re-Visions of Shakespeare. Marianne Novy. Urbana \& Chicago: University of Illinois Press. 137-149. 